\title{
LANGUAGE AND SPEECH IN THE SPACE OF CULTURE: INTERPRETATION AND REINTERPRETATION
}

\author{
Polina S. Volkova \\ Kuban State Agrarian University named after I.T. Trubilin, Krasnodar, Russia
}

\begin{abstract}
The author focuses on the experience of the thought-speech activity of the subject. Its consideration is carried out through the prism of such areas of humanitarian science as the philosophy of language, ontology, psychology, cultural studies, and art history. The necessity for interdisciplinary approach is explained by the fact that the comprehension of the essence of thought-speech activity within any science impoverishes the notion of thinking culture and speech culture of a subject involved in interaction with himself and with other people. In this context, as the basic category, the author determines the individual conceptual system of the subject of speech, the dual character of which is recognized, on the one hand, at the level of an expedient, automatically triggered by the nature of the information process, realized through interpretation and representing the experience of self-organization of the system; on the other hand, level of an individual conceptual system organization as a purely human activity (thought activity), realized through reinterpretation. If in the first case nature pre-mines over man, as a result of which life is subordinated to the satisfaction of natural reflexes (instincts), in the second case there is a reflection providing the subject of thought-speech activity with freedom over natural instincts. It is asserted that in the second case, the consciousness acts as a true regulator of the life of a linguistic personality.
\end{abstract}

Key words: thinking, meaning, meaning, individual consciousness, collective unconscious.

Citation. Volkova P.S. Language and Speech in the Space of Culture: Interpretation and Reinterpretation. Vestnik Volgogradskogo gosudarstvennogo universiteta. Seriya 2, Yazykoznanie [Science Journal of Volgograd State University. Linguistics], 2017, vol. 16, no. 4, pp. 207-214. (in Russian). DOI: https://doi.org/10.15688/ jvolsu2.2017.4.20

УДК $81: 008$

ББК 81.006 .3
Дата поступления статьи: 14.09.2017

Дата принятия статьи: 10.11.2017

\section{ЯЗЫК И РЕЧЬ В ПРОСТРАНСТВЕ КУЛЬТУРЫ: ИНТЕРПРЕТАЦИЯ И РЕИНТЕРПРЕТАЦИЯ}

\section{Полина Станиславовна Волкова}

Кубанский государственный аграрный университет им. И.Т. Трубилина, г. Краснодар, Россия

\begin{abstract}
Аннотация. В центре внимания автора статьи - опыт мыслеречевой деятельности субъекта, рассмотрение которой осуществляется сквозь призму таких областей гуманитарной науки, как философия языка, онтология, психология, культурология, искусствознание. Необходимость учета межпредметных связей обусловлена тем обстоятельством, что постижение сути мыслеречевой деятельности в пределах какой-либо одной науки обедняет представление о культуре мышления и культуре речи субъекта, включенного во взаимодействие как с самим собой, так и с другими людьми. В данном контексте в качестве базовой категории автор определяет индивидуальную концептуальную систему субъекта речи, двойственный характер которой опознается, с одной стороны, на уровне целесообразного, автоматически запущенного природой информационного процесса, реализуемого посредством интерпретации и являющего собой опыт самоорганизации системы; с другой стороны, на уровне организации индивидуальной концептуальной системы как сугубо человеческой деятельности (мыследеятельности), реализуемой посредством реинтерпретации. Если в первом случае природа доминирует над человеком, вследствие чего жизнь подчинена удовлетворению природных () рефлексов (инстинктов), то во втором случае возникает рефлексия, обеспечивающая субъекту мыслерече-
\end{abstract}


вой деятельности свободу над природными инстинктами. Утверждается, что во втором случае сознание выступает подлинным регулятором жизни языковой личности.

Ключевые слова: мышление, значение, смысл, индивидуальное сознание, коллективное бессознательное.

Цитирование. Волкова П. С. Язык и речь в пространстве культуры: интерпретация и реинтерпретация // Вестник Волгоградского государственного университета. Серия 2, Языкознание. - 2017. - Т. 16, № 4. C. 207-214. - DOI: https://doi.org/10.15688/jvolsu2.2017.4.20

Все в жизни цепью связано нетленной, Все включено в один круговорот. Сорвешь цветок, а где-то во вселенной В тот миг звезда погаснет и умрет. Лев Куклин

За то, что я пережил и понял в искусстве, я должен отвечать своей жизнью, чтобы все пережитое и понятое не осталось бездейственным в ней.

М.М. Бахтин

\section{Вступление: Культура как связь}

Выступая на одном из каналов телевидения России, сценарист, поэт, драматург и педагог Юрий Арабов сказал, что «Мона Лиза» и «Венера Милосская» - это всего лишь консервы для туристов. Если иметь в виду то, что ценность консервов определяется, как правило, их готовностью к употреблению, точка зрения Ю. Арабова, несмотря на ее парадоксальность, становится вполне понятной. В целом знание художественных образцов, прославивших их создателей, никоим образом не может служить показателем высокого уровня развития человека, тем более знаком его причастности к культуре. Быть культурным, по Ю. Арабову, - значит непрестанно осознавать свою включенность во все, что происходит вокруг, ибо культура - это, прежде всего, связь (Программа «Линия жизни» на телеканале «Культура» от 12.02.2016. URL: http://tvkultura. ru/anons/show/brand_id/20872/episode_id/ 1268033/).

Полностью соглашаясь с мастером, заметим, что, когда одно из базовых определений культуры звучит как «возделывание почвы», нельзя забывать о первостепенной необходимости возделывания собственно человеческой личности по той простой причине, что человек не данность, а всего лишь задание. Специально оговорим, что слово почва можно считать метонимическим наименованием природы, частью которой каждый из нас является. Принимая во внимание тот факт, что каждое целое состоит из частей аналогично тому, как часть вмещает в себя целое, нельзя не признать верность следующего положения: целостность нашей личности как части целого также представляет собой сумму некоторых частей. Как наше единство с миром, реализуемое в диалектике части и целого, определено природной закономерностью, так и целостность каждого из нас есть не что иное, как обусловленное природой единство. Соответственно, чтобы заявить о себе как о существе надприродном, людям необходимо исключительно самостоятельно осуществлять связь всех своих элементов, не полагаясь на природную данность. Каким образом осуществляется искомое единство природного и надприродного?

\section{Индивидуальная концептуальная система: природное и надприродное}

Прежде всего обратим внимание на тот момент, что природная данность может быть представлена двумя сторонами психической жизни субъекта, опознаваемыми во взаимодействии коллективного бессознательного и индивидуального сознания. Поскольку их соединение «в пространстве и времени» есть результат естественного, протекающего безотносительно к субъекту процесса развития, мы, вслед за М. Бахтиным, имеем все основания квалифицировать такое целое как механическое. Несмотря на то что «части такого целого... “лежат" рядом и соприкасаются друг с другом, ...в себе они чужды друг другу» [Бахтин, 1994а, с. 257].

Суть такой связи в аспекте философии языка раскрывает Р. Павиленис [Павиленис, 1983], который утверждает, что каждый человек является носителем индивидуальной концептуальной системы, представленной неязыковыми и языковыми элементами. Несмотря на то что становление неязыковых 
элементов системы происходит на основе информации, получаемой посредством органов чувств (зрение, слух, осязание и т. п.), чувственное происхождение таких элементов не отменяет их интеллектуального статуса, поскольку неязыковые элементы системы преобразуют сенсорный поток таким образом, что совокупность ощущений трансформируется в раздельность впечатлений, функционирующую на уровне диалога модальностей.

В качестве примера, косвенно иллюстрирующего взаимоотношения, складывающиеся между поступающим извне сенсорным потоком и преобразующими его неязыковыми элементами, обратимся к книге А. Вознесенского «Прорабы духа». На ее страницах поэт рассказывает о своем знакомстве с А. Крученых - одним из представителей Серебряного века. В общении со своим визави А. Крученых “овнешняет” свой внутренний опыт как нерасчлененную целостность, одновременно представленную звуком, цветом и формой. В противоположность ему А. Вознесенский «раскладывает» передаваемую ему собеседником совокупность ощущений. Например:

«Ю-юйца!» - зачинает он, у вас слюнки текут, вы видите эти, как юла, крутящиеся на скатерти крашеные пасхальные яйца... «Зухрр», - не унимается зазывала, и у вас тянет во рту, хрупает от засахаренной хурмы, орехов, зеленого рахат-лукума и прочих сладостей Востока, но главное - впереди. Голосом высочайшей муки и сладострастия, изнемогая, становясь на цыпочки и сложив губы как для свиста или поцелуя, он произносит на тончайшей бриллиантовой ноте: «Мизюнь, мизюнь!...» Все в этом «мизюнь» - и юные барышни с оттопыренным мизинчиком, церемонно берущие изюм из изящных вазочек, и обольстительная весенняя мелодия Мизгиря и Снегурочки, и, наконец, та самая щемящая нота российской души и жизни, нота тяги, утраченных иллюзий, что отозвалась в Лике Мизиновой и в «Доме с мезонином», - этой всей несбывшейся жизнью выдохнутый зов: «Мисюсь, где ты?» [Вознесенский, 1994, с. 21].

В итоге читатель приобщается к раздельности полученных Вознесенским в процессе общения с Крученых представлений, будучи вовлеченным в диалог модальностей (подробно об этом см. в: [Коляденко, 2005]). Еще раз подчеркнем, что данный пример может служить лишь косвенной иллюстрацией интересующего нас опыта перевода совокупности ощущений в раздельность впечатлений, поскольку А. Вознесенский делится с нами своими представлениям посредством слова, тогда как неязыковые элементы дифференцируют сенсорный поток безотносительно к языку, опираясь исключительно на коррелирующие с тем или иным каналом восприятия модальности.

Поскольку неязыковые элементы системы, становление которых происходит на основе информации, получаемой из внешнего мира посредством чувственных каналов восприятия, предшествуют возникновению языковых элементов, то именно они и являют собой тот «материал», из которого формируются последние. Такое положение дел обусловлено функцией элементов языковой системы кодировать чувственный (невербальный) опыт с целью последующего манипулирования им через манипулирование вербальными элементами. Если проводить аналогии между выделенными М. Бахтиным моментами текста - «данным» и «созданным», то по отношению к человеку как тексту (В. Налимов) данное звучит в унисон с неязыковыми элементами системы аналогично тому, как созданное звучит в унисон с языковыми элементами [Бахтин, 1994а]. Подтверждает представленную позицию тот факт, что языковые элементы кодируют сугубо индивидуальный внутренний опыт, присущий конкретной концептуальной системе. Причем данное сохраняется в созданном, с одной стороны, в своей неизменности, с другой - в некоем новом качестве, что свидетельствует о единстве самой концептуальной системы.

\section{Индивидуальная концептуальная система: интерпретация и реинтерпретация}

Достижение обозначенного единства Р. Павиленис связывает с опытом интерпретации, имея в виду ситуацию, когда релевантная несовместимость, или - иначе - неизбежное для каждой индивидуальной концептуальной системы несовпадение неязыковых элементов с языковыми, преодолевается через согласование одного с другим. В целом речь идет о непрерывном конструировании внеш- 


\section{МАТЕРИАЛЫ И СООБЩЕНИЯ}

ней по отношению к концептуальной системе информации во внутреннюю. Сначала посредством интерпретации сенсорного потока неязыковыми элементами система становится обладателем информации, которая представлена разными модальностями, затем посредством интерпретации этих разных модальностей языковыми элементами система овладевает возможностью манипулировать этой внутренней информацией через манипулирование элементами языка. Другими словами, принцип интерпретации обеспечивает переход внешней информации во внутреннюю с последующим ее переводом во вне.

Заметим, что обращение к категории интерпретации в отношении индивидуальной концептуальной системы как нельзя более отвечает опыту исполнительской практики: части целостной системы поставлены перед необходимостью выполнять каждая свою «работу», согласовывая неизбежные во взаимоотношениях друг с другом противоречия. Аналогично тому, как исполнительская интерпретация представляет собой относительно самостоятельную деятельность субъекта (подробно об этом см. в: [Гуренко, 1982]), поскольку ее возникновение обусловлено необходимостью «перевыражать» замысел композитора, осуществляя «перевод» нотного текста в звучащий, интерпретация одних элементов индивидуальной концептуальной системы другими элементами также оказывается лишь относительно самостоятельной.

По отношению к субъекту как носителю индивидуальной концептуальной системы сама система выступает некой данностью, в рамках которой становление неязыковых и языковых элементов системы, демонстрирующих единство природного и социального, требуют от субъекта минимальной активности. Другими словами, как накопление информации, интерпретацию которой осуществляют неязыковые элементы системы, осуществляется в процессе восприятия субъектом окружающего его мира, так и интерпретация языковыми элементами чувственного опыта предполагает знание языка (как правило, его освоение обеспечивается такими социальными институтами, как семья, школа и т. п.).

Кто же является подлинным «обладателем» индивидуальной концептуальной системы, осуществляя реинтерпретацию составляющих ее элементов? Поскольку реинтерпретация являет собой процесс тотального переосмысления изначально существующего опыта (подробно об этом см. в: [Волкова, 2008]), ее может осуществлять субъект, чья деятельность была бы исключительно самостоятельной и всякий раз оценивалась бы по отношению к элементам самой системы как первичная.

Ответ на поставленный вопрос можно получить, произведя проекцию категорий, разрабатываемых Р. Павиленисом, в пространства коллективного бессознательного, коррелирующего с неязыковыми элементами системы, и индивидуального сознания, которое коррелирует с языковыми элементами системы. Точка зрения Р. Павилениса, считавшего неязыковые элементы системы доминирующими, согласуется с позицией ряда исследователей, работающих в русле юнговской парадигмы. Так, несмотря на разность терминологического аппарата, философы (В.М. Бакусев), психологи (А.Н. Леонтьев), лингвисты (А.А. Леонтьев), филологи (М.М. Бахтин), культурологи (А.К. Устин) признают главенство коллективного бессознательного, отводя ему определяющую роль в психической жизни субъекта. В качестве аргумента выдвигается тезис о том, что именно коллективное бессознательное предстает как наиболее общая психике и внешнему миру сфера. Другими словами, будучи своеобразными «щупальцами» нашего внутреннего мира, которые нацелены на мир внешний, коллективное бессознательное выступает для высших слоев психики в качестве материи, уподобляемой материальности окружающего субъекта мира. При этом сам термин «коллективное бессознательное» не означает отсутствия в такой материи каких-либо примет сознания (интеллекта). Напротив, присутствие сознания в бессознательном не отрицается, однако такое сознание стоит, по образному выражению В. Бакусева, «спиной» к бессознательному, вследствие чего бессознательное «не знает» не только того, что представляет собой сознание, но и того, что это сознание - его. В противном случае бессознательное стало бы сознанием [Бакусев, 1992, с. 254].

Если бессознательное «не знает», что пульсирующие в нем «токи и смыслы целесо- 
образности» (А. Лосев) - это приметы его собственного сознания, то тогда в некоторой степени они - эти приметы - и не его. Эти проблески сознания не являются и принадлежностью сознания, поскольку они приходят к нему со стороны бессознательного в виде определенных типов поведения, эмоциональных реакций, образов спонтанных фантазий или сновидений. При этом, как пишет В. Бакусев, будучи «чисто природным, автоматически целесообразным процессом», коллективное бессознательное «может быть использовано и на благо, и во вред целостной душе» [Бакусев, 1992, с. 258]. Оставляя свободу выбора за сознанием, выскажем следующее предположение.

В случае вреда, который может нанести коллективное бессознательное целостной душе, речь идет о ситуации, когда индивидуальное сознание поглощается содержаниями бессознательного. Такое «поглощение» может происходить как со стороны неязыковых элементов - напомним, речь идет об определенных типах поведения, эмоциональных реакциях и т. п., так и со стороны языковых элементов. Имеется в виду становление языковой компетентности субъекта по присущим каждому языку правилам. Такие правила В. Гумбольдт определял как чистое и «голое», то есть обобщенное и потому «мертвое» абстрактное «артикуляционное чувство» [Гумбольдт, 1984, с. 70-71]. Посредством последнего субъект не только усваивает и использует прежние значения, но и расширяет сферу их пользования за счет освоения внешней по отношению к индивидуальной концептуальной системе информации, которая представлена исключительно вербальными, то есть сугубо языковыми, концептами.

Подобное положение дел редко осознается носителем языка как знак ущербности, поскольку неизбежная утрата сознания, выступающего в качестве подлинного регулятора жизнедеятельности субъекта, компенсируется способностью субъекта оперировать значениями: «значение - представитель и носитель культуры» [Богин, 2011], способность говорить автоматически делает носителя языка представителем социума, уравнивая его в правах с остальным большинством. По сути, об ущербности обособленного от неязыковых элемен- тов системы языкового сознания, которое существует само по себе, безотносительно к целостной личности, пишет и В. Гаврилин, размышляя о современной социокультурной ситуации: «Наши русские гении, - пишет отечественный композитор, - дрались за русский язык, а тут появляются альмеи (так называли проституток в Египте. - В.Г.), корежат его, и им аплодируют» [Гаврилин, 2003, с. 278].

Отмеченную обособленность одних элементов системы (неязыковых) от других (языковых) мы характеризуем как внешнюю, механическую связь, обусловленную исключительно природным, действующим в нас помимо нас самих началом.

Напротив, в случае несомненного блага речь идет о выделении личности из коллективных основ собственной психики или о снятии индивидуальным «Я» негативности бессознательного в коллективном. Результатом такого снятия становится отказ от индивидуализма и обретение «Я» коллективного характера. Специально заметим, что ситуация, в рамках которой «Я-единственный из себя исхожу, а всех других нахожу...»-в корне отличается от бессознательной коллективности, поскольку очевидна их «онтологически-событийная разнозначность» [Бахтин, 19946 , с. 66] ${ }^{1}$.

Процесс согласования противоречий, определяющий собой взаимодействие коллективного бессознательного с индивидуальным «Я» или, что то же - неязыковых и языковых элементов системы, со всей очевидностью опознается в словах Р. Вагнера, сказанных им по поводу хорового финала Девятой симфонии Л. ван Бетховена: если «инструменты передают изначальные звуки мироздания и природы; то, что они выражают, нельзя точно определить, нельзя ясно установить их характер, ибо они передают изначальные чувства, как они возникали из хаоса первозданного мира, возможно, еще до появления человека, который мог бы принять эти чувства в свое сердце», то «человеческий голос выражает человеческое сердце и его замкнутое индивидуальное чувство, что с неизбежностью ограничивает его характер. Соответственно, центральная задача, которая стояла перед Бетховеном, - соединить эти два элемента и слить их воедино» [Вагнер, 1978, с. 103]. 


\section{МАТЕРИАЛЫ И СООБЩЕНИЯ}

Знаменательно, что «присоединение этого второго элемента окажет, по мысли композитора, благотворное и смягчающее воздействие на борьбу изначальных чувств, введет их поток в определенное общее русло, а человеческое сердце, восприняв эти изначальные ощущения, станет шире и сильней и обретет способность осознать в себе божественную сущность, до того жившую в нем как смутное предчувствие высшего существа» [Вагнер, 1978, с. 103]. Оставляя в стороне вопрос о том, насколько опыт Бетховена способствует актуализации отмеченного Вагнером процесса у слушателя ${ }^{2}$, подчеркнем: по сути, именно осознание своего единства со всем окружающим миром ведет к отказу жить исключительно по той программе, которую в человека заложила природа, в этом отказе безусловная свобода личности. Имеется в виду такая личность, которая, поднимаясь над природной данностью, выходит за рамки системы, освобождаясь от ее власти. Будучи «хозяином положения», она объединяет элементы системы в себе самой, выступая в качестве целевой причины, притягивающей к себе все психические процессы. К-Г. Юнг называл такую личность Homo totus - личность во всей своей целокупности или, что то же - caмость. В силу своей принципиально двойственной природы она и сознательна, и бессознательна, но одновременно и трансцендентна по отношению к обоим своим модусам.

Таким образом, мы ответили на вопрос, кто выступает подлинным обладателем всей полноты сознания, осуществляя реинтерпретацию элементов индивидуальной концептуальной системы. Этот процесс предполагает следующие процедурные нормы:

1) закодированная языковыми элементами невербальная информация декодируется, актуализируя представленный диалогом модальностей чувственный опыт субъекта, что делает возможным обратный переход от внешних знаков речевого потока к внутренним; 2) чувственный опыт кодируется либо языковыми элементами системы, либо неязыковыми.

Важность такого опыта обусловлена тем, что в процессе реинтерпретации формируется образ образа, то есть субъективный образ внешнего по отношению к носителю языка мира, каким он запечатлен в информации, полученной посредством чувственных каналов восприятия. Имеется в виду сугубо самостоятельная деятельность (мыследеятельность) языкового носителя, обусловливающая уход от «равнодушных значений» (А. Н. Леонтьев) к «значению для меня». Первоначально открытие «значения для меня» осуществляется исключительно на уровне неязыковых элементов системы, становление которых происходит посредством межчувственной интеграции, или в пространстве диалога модальностей. Выступая аналогом личностного смысла, такое открытие требует своего последующего выражения, реализуемого либо посредством языковых элементов системы, если речь идет о слове, либо неязыковых элементов, если перед нами художественное полотно или музыкальная композиция.

В открытии «значения для меня» деятельность Homo totus являет собой первичную деятельность, поскольку, актуализируя личностный смысл, носитель индивидуальной концептуальной системы выступает в роли его (смысла) первооткрывателя. Будучи "овнешненным”, последний служит «пусковым механизмом» мыслеречевой деятельности другого субъекта, побуждая его к саморазвитию и личностному росту. В обозначенном процессе сама система, включая как неязыковые, так и языковые элементы, выступает на уровне такой данности, опираясь на которую личность оказывается способной к самосозданию (самосозиданию). Возвращаясь к аналогии с исполнительской практикой, заметим, что в случае реинтерпретации речь идет об исполняющем свое собственное произведение композиторе. Вбирая в себя весь предшествующий опыт, композитор «переплавляет» все, чем располагает на данный момент культура, в исключительно авторское высказывание, что позволяет квалифицировать его деятельность как первичную, а потому самостоятельную.

\section{Заключение: текст культуры как опыт диалога сознаний}

Подытоживая все вышеизложенное, заметим, что в случае соблюдения фундаментального принципа интерпретации концептуальная система реализуется на уровне само- 
П.С. Волкова. Язык и речь в пространстве культуры: интерпретация и реинтерпретация

организации. Имеется в виду такой режим ее асимметричного функционирования, который «поддерживается согласованностью разнонаправленных асимметрий и функциональных симметрий более частного порядка, возникающих спонтанно» [Москальчук, 2010, c. 195]. Следование опыту реинтерпретации, напротив, приводит систему к организации как направленному процессу развертывания инвариантных особенностей ее структурных элементов.

По всей видимости, благой для индивидуальной концептуальной системы опыт с наибольшей полнотой будет закрепляться в процессе работы с текстами культуры. Верность подобного вывода зиждется на том основании, что собственно текст демонстрирует собой очевидную для субъекта связь, ибо «метафора Текста - сеть» (Р. Барт). Здесь этимология лексемы текст полностью соответствует его обозначаемого: Textum (от лат. texto) - «сотканный, сплетенный» (Ю. Лотман). Другими словами, именно текст культуры выступает полем методологических операций, совершая которые мыслеречевой субъект с неизбежностью реализует единство рационального и иррационального, или дискретного и континуального. Соответственно, включение в образовательное пространство самых разных как вербальных и невербальных (музыкальных, изобразительных, пластических и т. п.), так и синтетических, то есть построенных на взаимодействии музыки, слова, живописи, пластике человеческого тела и т. п., текстов культуры обеспечит целенаправленное движение от «равнодушных значений» к «личностным смыслам».

\section{ПРИМЕЧАНИЯ}

${ }^{1}$ У А.Н. Леонтьева подобный опыт обобщен в следующем определении: «Я нахожу и/или имею свое "я" не в себе самом (его во мне видят другие), а вовне меня существующем - в собеседнике, в любимом, в природе» [Леонтьев, 1983, с. 241].

${ }^{2}$ Известно, что на фоне звучащего хорового финала Девятой симфонии Л. ван Бетховена С. Кубрик счел возможным демонстрировать кадры фашистской хроники, что в корне противоречит идейной установке композитора, которая звучит в унисон с концептуальной информацией «Оды к радости» Шиллера: «Обнимитесь, миллионы!» Этико-эс- тетическая интерпретация такого режиссерского решения предложена в: [Шаховский, Волкова, 2015].

\section{СПИСОК ЛИТЕРАТУРЫ}

Бакусев В. М., 1992. В земле человеческой : проблема культуры и творчество К.Г. Юнга // Юнг К. Г. Феномен духа в искусстве и науке : собр. соч. М. : Ренессанс. Т. 15. С. 229-270.

Бахтин М. М., 1994а. Проблема содержания, материала и формы в словесном художественном творчестве // Работы 1920-х годов. Киев : Next. C. $257-318$.

Бахтин М. М., 1994б. К философии поступка // Paботы 1920-х годов. Киев : Next. С. 9-68.

Богин Г. И., 2001. Обретение способности понимать: Введение в герменевтику. М. : Психология и бизнес ОнЛайн. 731 c. URL: http://lineburg.ru/ philosophy/bogin_g_i_obretenie_ sposobnosti_ponimat', vvedenie_v_ germenevtiku_tver' 2001_731_s.html/.

Вагнер Р., 1978. Паломничество к Бетховену / пер. с нем. И. Татариновой // Рихард Вагнер. Изданные работы / сост. и коммент. И. А. Барсовой, С. А. Ошерова. М. : Искусство. С. 85-106.

Вознесенский А. А., 1994. Прорабы духа. М. : Советский писатель. $496 \mathrm{c}$.

Волкова П. С., 2008. Реинтерпретация художественного текста (на материале искусства XX века). Краснодар : ООО Издательский дом «ХОРС». $200 \mathrm{c}$.

Гаврилин В. А., 2003. О музыке и не только... Записи разных лет / сост. Н. Е. Гаврилина, В. Г. Максимов. СПб. : Композитор. 344 с.

Гумбольдт В. фон, 1984. Форма языков // Избранные труды по языкознанию. М. : Прогресс. C. 69-74.

Гуренко Е. Г., 1982. Проблемы художественной интерпретации (философский анализ). Новосибирск : НГК. $256 \mathrm{c}$.

Коляденко Н. П., 2005. Синестетичность музыкально-художественного сознания (на материале искусства XХ века). Новосибирск : НГК. 392 с.

Леонтьев А. Н., 1983. Из дневниковых записей // Избранные психологические произведения : в 2 т. М. : Педагогика. Т. 1. С. 240-242.

Москальчук Г. Г., 2010. Структура текста как синергетический процесс. М. : Едиториал УРСС. 296 с.

Павиленис Р. И., 1983. Проблема смысла. М. : Мысль. 286 с.

Шаховский В. И., Волкова П. С., 2015. Этико-эстетический аспект экологичности эмоций в произведениях искусства // Вестник российского университета Дружбы народов. Серия: Лингвистика. № 1. С. 31-41. 


\section{МАТЕРИАЛЫ И СООБЩЕНИЯ}

\section{REFERENCES}

Bakusev V.M., 1992. In the human earth: the problem of culture and art of K.G . Jung. Jung K.G. Fenomen dukha v iskusstve i nauke (Sobr. soch. T. 15). Moscow, Renessans Publ., pp. 229-270. (in Russian).

Bakhtin M.M., 1994a. The problem of content, material and form in verbal artistic creation. Bakhtin M. M. Raboty 1920-h godov. Kiev, Next Publ., pp. 257318. (in Russian).

Bakhtin M.M., 1994b. To the philosophy of the act. Bakhtin M. M. Raboty 1920-kh godov. Kiev, Next, pp. 9-68. (in Russian).

Bogin G.I., 2001. Gaining the ability to understand: Introduction to hermeneutics. Moscow, Psikhologiya i biznes OnLayn. 731 p. URL: http:// lineburg.ru/philosophy/bogin_g_i _obretenie_sposobnosti_ponimat'_vvedenie v_germenevtiku_tver'_2001_731_s.html. (in Russian).

Vagner R., 1978. A pilgrimage to Beethoven. Barsova I.A., Osherov S.A. Rihard Vagner. Izdannye raboty. Moscow, Iskusstvo Publ., pp. 85-106. (in Russian).

Voznesenskiy A.A., 1994. Superintendents of the spirit. Moscow, Sovetskiy pisatel Publ. 496 p. (in Russian).
Volkova P.S., 2008. Reinterpretation of the art text (on the material of the 20th-century art). Krasnodar, KhORS Publ. 200 p. (in Russian).

Gavrilin V.A., 2003. About the music... Records of different years. Sant Petersburg, Kompozitor Publ. 344 p. (in Russian).

Gumboldt W. fon, 1984. Form of languages. W. fon Gumboldt. Izbrannye trudy po yazykoznaniyu. Moscow, Progress Publ. 400 p. (in Russian).

Gurenko E.G., 1982. Problems of literary interpretation (philosophical analysis). Novosibirsk, NGK Publ. 256 p. (in Russian).

Kolyadenko N.P., 2005. Synesthetically musical and artistic consciousness (based on the art of the $20^{\text {th }}$ century). Novosibirsk, NGK Publ. 392 p. (in Russian).

Leontyev A.N., 1983. Extracts from diaries. Izbrannye psikhologicheskie proizvedeniya: V $2 t$. Moscow, Pedagogika Publ, vol. 1, pp. 240-242 (in Russian).

Moskalchuk G.G., 2010. Text structure as a synergetic process. Moscow, Editorial URSS. 296 p. (in Russian).

Pavilenis R.I., 1983. The problem of meaning. Moscow, Mysl Publ. 286 p. (in Russian).

Shakhovskiy V.I., Volkova P.S., 2015. Ethico-aesthetic aspect of sustainability of emotions in works of art. Vestnik rossiyskogo universiteta Druzhby narodov. Seriya lingvistika [Russian Journal of Linguistics], no 1, pp. 31-41. (in Russian).

\section{Information about the Author}

Polina S. Volkova, Doctor of Sciences (Philosophy), Doctor of Arts, Candidate of Sciences (Philology), Professor, Department of Sociology and Culturology, Kuban State Agrarian University named after I.T. Trubilin, Kalinin St., 13, 350044 Krasnodar, Russia, polina7-7@yandex.ru, http://orcid.org/00000002-2424-7521

\section{Информация об авторе}

Полина Станиславовна Волкова, доктор философских наук, доктор искусствоведения, кандидат филологических наук, профессор кафедры социологии и культурологии, Кубанский государственный аграрный университет им. И.Т. Трубилина, ул. Калинина, 13, 350044 г. Краснодар, Россия, polina7-7@yandex.ru, http://orcid.org/0000-0002-2424-7521 